\title{
Satisfaction and attitudes of Zagreb medical students towards online education during the COVID-19 pandemic
}

\author{
Authors: Robert Marčec ${ }^{1}$, Matea Majta ${ }^{1}$, Robert Likić ${ }^{1,2}$ \\ ${ }^{1}$ School of Medicine, University of Zagreb \\ ${ }^{2}$ Clinical Hospital Centre Zagreb, Department of Internal Medicine, Unit for Clinical Pharmacology \\ DOI: https://doi.org/10.26800/LV-142-supp5-47

\section{Introduction}

In March 2020 all in-person teaching activities at the University of Zagreb School of Medicine ceased due to COVID-19 pandemic and online classes were introduced till the end of the academic year. Both teachers and students experienced a completely new teaching environment.

\begin{abstract}
Aim
Our aim was to gain insight regarding overall attitudes of Zagreb medical students towards conducted online education and to identify factors influencing students' satisfaction.
\end{abstract}

\section{Materials and Methods}

An online anonymous survey was distributed in August 2020 to all medical students at the Zagreb Medical School. It consisted of 30 five-point Likert scale questions grouped in 4 categories (online education content, interactions in online education, online clinical education and online exams). An analysis of variance (ANOVA) was performed on the gathered data to identify variables influencing student satisfaction, where variable impact was expressed by eta squared (ES).

\section{Results}

The online questionnaire was completed by 483 students (response rate: $27 \%$; $n=483 / 1800,330$ female(68\%) and 155 male students(32\%)) and the average satisfaction was $2.69 \pm 1.10$ (mean \pm SD). Further analysis indicated that responders' attitudes towards online teaching seem to be most strongly influenced by (in decreasing order): the quality and quantity of online content provided $(E S=0.246)$, academic year $(E S=0.174)$, readiness to embrace online teaching as a replacement for classical education $(E S=0.059)$ and preference for traditional teaching $(E S=0.040)$.

\section{Conclusion}

The COVID-19 pandemic and online education have continued into the next academic year. We hope that the factors influencing student's satisfaction identified in our study can serve as a reference for improvement of online education at our and other medical schools. Some of the identified factors like readiness to embrace online education and preference for traditional teaching can be difficult to change, so we suggest improving the quality and quantity of online content provided by medical schools as the main intervention in order to increase students' satisfaction with online education.

Keywords: COVID-19, online education, student satisfaction 